\title{
The estrogen receptor coactivator AIB1 is a new putative prognostic biomarker in ER-positive/HER2-negative invasive lobular carcinoma of the breast
}

\author{
Ulrik Narbe $^{1,4} \oplus$ - Martin Sjöström ${ }^{1} \cdot$ Carina Forsare $^{1} \cdot$ Pär-Ola Bendahl ${ }^{1} \cdot$ Sara Alkner ${ }^{1,3}$. \\ L. M. Fredrik Leeb-Lundberg ${ }^{6} \cdot$ Kristina Lövgren $^{1} \cdot$ Lisa Rydén $^{2,5} \cdot$ Christian Ingvar $^{2,5} \cdot$ Mårten Fernö $^{1}$
}

Received: 21 October 2018 / Accepted: 18 January 2019 / Published online: 22 February 2019

(c) The Author(s) 2019

\begin{abstract}
Purpose According to the 2017 St Gallen surrogate definitions of the intrinsic subtypes, Ki67, progesterone receptor (PR) and Nottingham histological grade (NHG) are used for prognostic classification of estrogen receptor (ER) positive/HER2negative breast cancer into luminal A- or luminal B-like. The aim of the present study was to investigate if additional biomarkers, related to endocrine signaling pathways, e.g., amplified in breast cancer 1 (AIB1), androgen receptor (AR), and G protein-coupled estrogen receptor (GPER), can provide complementary prognostic information in a subset of ER-positive/ HER-negative invasive lobular carcinoma (ILC).

Methods Biomarkers from 224 patients were analyzed immunohistochemically on tissue microarray. The primary endpoint was breast cancer mortality (BCM), analyzed with 10- and 25-year follow-up (FU). In addition, the prognostic value of gene expression data for these biomarkers was analyzed in three publicly available ILC datasets.

Results AIB1 (high vs. low) was associated to BCM in multivariable analysis (adjusted for age, tumor size, nodal status, NHG, Ki67, luminal-like classification, and adjuvant systemic therapy) with 10-year FU (HR 6.8, 95\% CI 2.3-20, $P=0.001$ ) and 25-year FU (HR 3.0, 95\% CI 1.1-7.8, $P=0.03$ ). The evidence of a prognostic effect of AIB1 could be confirmed by linking gene expression data to outcome in independent publicly available ILC datasets. AR and GPER were neither associated to BCM with 10-year nor with 25-year FU $(P>0.33)$. Furthermore, Ki67 and NHG were prognostic for BCM at both 10-year and 25-year FU, whereas PR was not.

Conclusions AIB1 is a new putative prognostic biomarker in ER-positive/HER2-negative ILC.
\end{abstract}

Keywords Invasive lobular carcinoma (ILC) - Amplified in breast cancer 1 (AIB1) · G protein-coupled estrogen receptor $($ GPER) $\cdot$ Androgen receptor (AR) · Prognostic biomarkers $\cdot$ Gene expression

Electronic supplementary material The online version of this article (https://doi.org/10.1007/s10549-019-05138-7) contains supplementary material, which is available to authorized users.

Ulrik Narbe

ulrik.narbe@med.lu.se

1 Department of Clinical Sciences, Division of Oncology and Pathology, Lund University, Medicon Village, 22381 Lund, Sweden

2 Department of Clinical Sciences, Division of Surgery, Lund University, Lund, Sweden

3 Skåne Clinic of Oncology, Skåne University Hospital, Lund, Sweden
4 Department of Oncology, Växjö Central Hospital, Växjö, Sweden

5 Department of Surgery, Skåne University Hospital, Lund, Sweden

6 Department of Experimental Medical Science, Lund University, Lund, Sweden 


\section{Introduction}

Estrogen receptor (ER) positive/HER2-negative breast cancer (BC) comprises $75-80 \%$ of all BC and this fraction is even higher $(>90 \%)$ in invasive lobular carcinoma (ILC) $[1,2]$. ILC is the second most common histological type of BC after invasive carcinoma of no special type (NST) and comprises approximately $10 \%$ of all invasive BC [3]. ILC has, compared to NST, distinct clinicopathological [4-7] and genomic features [8-10], and the response to adjuvant systemic therapy differs $[11,12]$. ILC also has a higher incidence of late recurrences but the overall prognosis seems to be the same $[8,12,13]$. In spite of the differences, current surgical and adjuvant treatments are similar. According to the 2017 St Gallen surrogate definitions of the intrinsic subtypes, proliferative fraction (Ki67), progesterone receptor (PR) status, and Nottingham histological grade (NHG) are used to classify ER-positive/ HER2-negative BC, as luminal A- or luminal B-like [14]. The luminal-like (HER2-negative) classification together with tumor size, axillary lymph node status (nodal status), and age is widely used in the clinic for prognostication and treatment decisions (endocrine therapy \pm chemotherapy). Nevertheless, these established prognostic variables still have their limitations, and there is an unmet need for additional prognostic biomarkers.

The androgen receptor (AR) belongs to the steroid nuclear receptor family and is frequently expressed in $\mathrm{BC}$, especially in ER-positive ILC (>85\%) [12, 15, 16]. The prognostic role of $\mathrm{AR}$ in $\mathrm{BC}$ is still unclear with some studies showing that AR positivity is associated with better prognosis [17-19] and others showing non-prognostic results $[20,21]$. The prognostic impact of AR in ILC is sparsely studied. Amplified in breast cancer 1 (AIB1) is a member of the steroid receptor coactivator family and interacts with ER. AIB1 is often expressed in BC and high AIB1 is implicated to be a negative prognostic factor and at the same time a predictive factor for response to endocrine therapy, although the findings are not unanimous [22-28]. G protein-coupled estrogen receptor (GPER) is distinct from ER and mediates non-genomic estrogenic responses. The reported prognostic value of GPER expression in BC is inconsistent [29-33]. Furthermore, lack of GPER in the plasma membrane (PM GPER-negativity) has been identified as a good prognostic feature in ER-positive BC [29]. To the best of our knowledge, no previous studies of either AIB 1 or GPER as a prognostic factor exclusively in ILC has been carried out.

The aim of the present study was to investigate if these new putative prognostic biomarkers (AR, AIB 1, and GPER), related to endocrine signaling pathways, can provide complementary information to established prognostic variables in a well-characterized case series of ER-positive/HER2-negative ILC with long-term follow-up (FU), and furthermore, if our immunohistochemical (IHC) findings could be validated in three independent publicly available gene expression ILC datasets [34-36].

\section{Patients and methods}

\section{Study population}

Between 1980 and 1991, 319 cases of female primary breast cancer were classified as ILC at the Departments of Pathology, Lund University Hospital, and Helsingborg Hospital, Sweden.

Reevaluation of histological type was performed for all tumors by two clinical pathologists, specialized in breast cancer, without knowledge of clinical data. In total, 95 patients were excluded leaving 224 patients available for further analyses in the present retrospective study (Fig. 1). A further subdivision of the ILCs was not performed. A minority (approximately 15\%) had an involvement of minor non-lobular invasive foci. E-cadherin was analyzed with IHC (Clone NCH-38, M3612 DAKO/Agilent 1:100) and loss of E-cadherin expression was found in $85 \%$ of the included tumors. The study population is based on a previously reported cohort [37], with the addition of 52 ILC cases from Helsingborg Hospital. Furthermore, this study has a longer FU time and all included biomarkers were assessed by IHC on tissue microarray (TMA), compared to previous whole tissue section analyses of ER, PR, HER2, and Ki67. NHG was reevaluated on whole tissue sections according to Elston and Ellis [38]. Patient and tumor characteristics were retrieved from clinical records and pathology reports (Table 1), as were FU data.

\section{TMA preparation}

TMAs were prepared from paraffin-embedded primary tumor blocks, using a manual arrayer (Beecher Instruments Inc.). Three cylindrical cores (triplets) with a diameter of 0.6 millimeter were taken from morphologically representative regions of the primary tumor blocks and transferred into a recipient paraffin block. Sections (3-4 $\mu \mathrm{m}$ ) were taken from each TMA block and transferred to glass slides.

\section{IHC staining and scoring of prognostic biomarkers}

IHC staining was carried out by an automatic immunostainer (TechMate ${ }^{\mathrm{TM}} 500$ Plus, DAKO), as previously described [39]. Each TMA section was digitally scanned and the images 
Fig. 1 Consort diagram: Breast cancer patients with tumors primarily classified as invasive lobular carcinomas (ILC) at the Department of Pathology, Skåne University Hospital Lund and Helsingborg Hospital, (1980-1991), $N=319$. ER positivity ( $\geq 1 \%$ ) was confirmed with IHC staining on tissue microarray in $N=200$ and whole tissue sections in $N=21$, and with cytosol-based methods in $N=3$ tumor samples

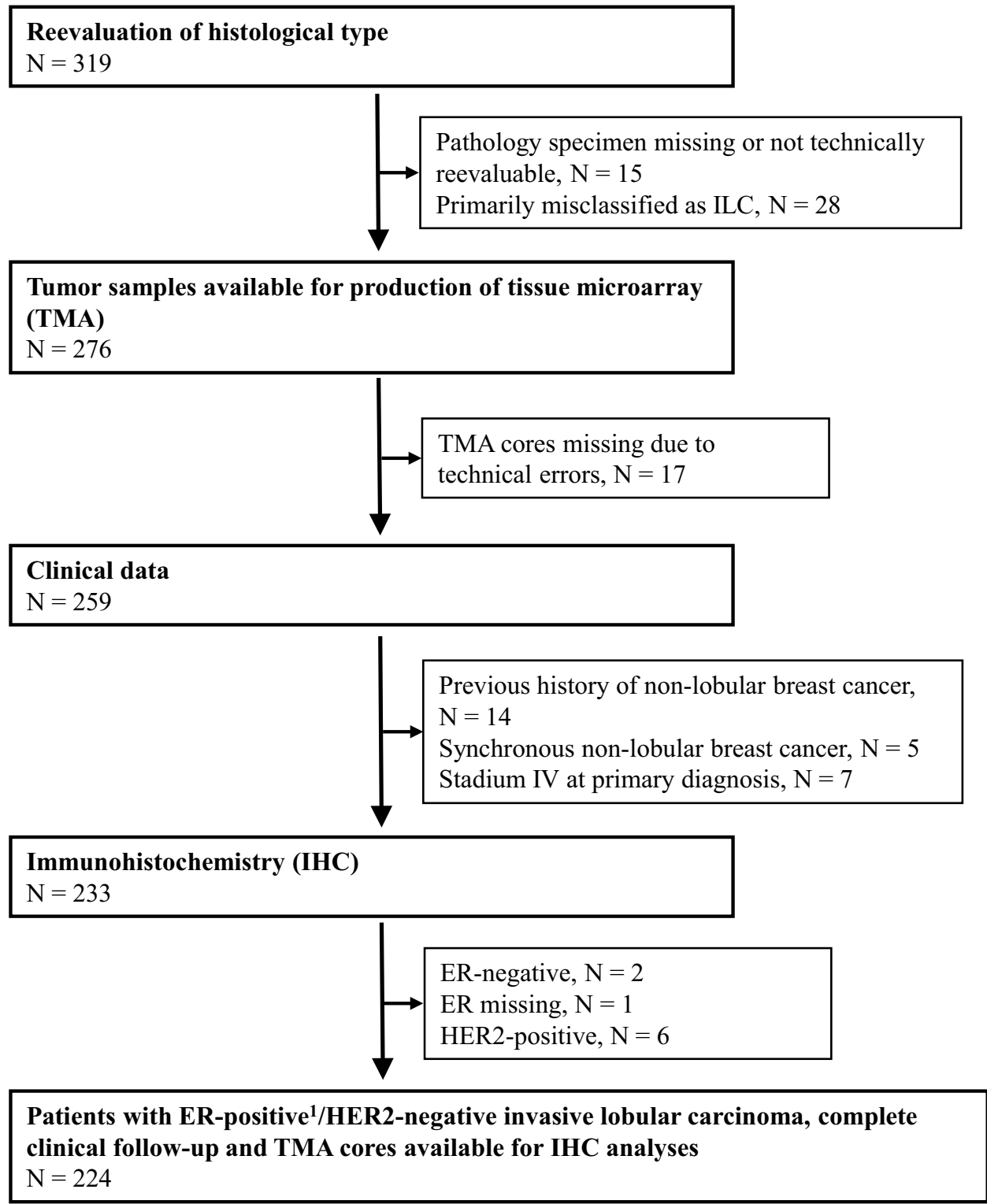

were evaluated using PathXL/Xplore (Philips). AIB1, AR, and GPER were assessed by two independent observers without knowledge of clinical data. Sections with less than 50 invasive cells were excluded. For the great majority (>90\%), more than 100 cells could be evaluated. Triplets of TMA cores from every tumor were assessed and in case of different staining scores between the cores, the highest score was chosen, except for GPER where the mean was used. Stains with discordant scoring between the observers were re-examined to reach consensus if the score differed by more than one step, otherwise the mean score was used. All cut-offs were decided according to a predefined protocol before linking protein expression to survival data. None of the biomarkers displayed any stromal staining. (Fig. 2).

For AIB1 detection, a monoclonal IgG antibody (Clone 34/AIB-1 1:40, BD Bioscience) was used. This antibody has a confirmed specificity [40] and has been used in several previous clinical studies [39-41]. AIB1 expression was analyzed in line with previous publications [27, 28, 39]. Each sample was semi-quantitatively scored from 0 to 3 for percentage of stained nuclei and staining intensity. IHC staining was exclusively seen in the nucleus. Proportion score 0 represented no stained nuclei, $1: 1$ to $10 \%, 2: 11$ to $50 \%$, and $3: 51$ to $100 \%$. Staining intensity 0 represented negative staining, 1 weak, 2 moderate, and 3 intense staining. Proportion and intensity scores were added to a total score ranging from 0 to 6 . The total scores were categorized into three groups: 1 (score $<5$ ), 2 (score 5 or $5.5^{1}$ ), and 3 (score 6$)$. In line with results from the

\footnotetext{
1 When averaging over two scores differing by one unit, the result
} will be non-integer. 
Table 1 Patient and tumor characteristics $(N=224)$

\begin{tabular}{|c|c|}
\hline Variables & No $(\%)$ \\
\hline \multicolumn{2}{|l|}{ Age } \\
\hline Median, years (range) & $62(36-87)$ \\
\hline \multicolumn{2}{|l|}{ Menopausal status } \\
\hline Premenopausal & $56(26)$ \\
\hline Postmenopausal & $161(74)$ \\
\hline Unknown & 7 \\
\hline \multicolumn{2}{|l|}{ Type of surgery } \\
\hline BCS & $49(22)$ \\
\hline BCS (no ALND) & 4 \\
\hline $\mathrm{BCS}+\mathrm{ALND}$ & 45 \\
\hline Mastectomy & $175(78)$ \\
\hline Mastectomy (no ALND) & 7 \\
\hline Mastectomy + ALND & 168 \\
\hline \multicolumn{2}{|l|}{ Tumor size (mm) } \\
\hline pT1 $(\leq 20)$ & $125(57)$ \\
\hline pT2 $(>20$ and $\leq 50)$ & $83(37)$ \\
\hline pT3 $(>50)$ & $13(6)$ \\
\hline Undefined & 3 \\
\hline \multicolumn{2}{|l|}{ Nodal status } \\
\hline pN-(ALND) & $129(61)$ \\
\hline $\mathrm{cN}-(\text { no ALND) })^{\mathrm{a}}$ & 11 \\
\hline $\mathrm{pN}+$ & $84(39)$ \\
\hline $\mathrm{pN} 1(1-3)$ & 40 (19) \\
\hline $\mathrm{pN} 2(4-9)$ & $33(15)$ \\
\hline $\mathrm{pN} 3(>9)$ & $11(5)$ \\
\hline \multicolumn{2}{|l|}{ Adjuvant therapy ${ }^{\mathrm{b}}$} \\
\hline None & $77(35)$ \\
\hline RT (total) & $110(49)$ \\
\hline CT (total) & $5(2)$ \\
\hline ET (total) & $91(41)$ \\
\hline RT (monotherapy) & $50(22)$ \\
\hline CT (monotherapy) & $3(1)$ \\
\hline ET (monotherapy) & $33(15)$ \\
\hline $\mathrm{RT}+\mathrm{CT}$ & $2(1)$ \\
\hline $\mathrm{RT}+\mathrm{ET}$ & $58(26)$ \\
\hline $\mathrm{CT}+\mathrm{ET}$ & $0(0)$ \\
\hline $\mathrm{RT}+\mathrm{CT}+\mathrm{ET}$ & $0(0)$ \\
\hline Unknown & 1 \\
\hline
\end{tabular}

$B C S$ Breast-conserving surgery, $A L N D$ Axillary lymph node dissection, $c$ clinical, $p$ pathological, $N$ - node negative, $\mathrm{N}+$ node positive

${ }^{a}$ The main reason for not undergoing ALND was a clinical node-negative (cN-) status in patients with co-morbidity and high age at diagnosis

${ }^{\mathrm{b}}$ Adjuvant therapy: $R T$ radiotherapy, $C T$ chemotherapy, $E T$ endocrine therapy

ER-positive/HER2-negative subgroup in a previous study from our group, the groups 1 and 2 were combined, resulting in two prognostic groups: high-AIB1 (score 6) and low-AIB1 (score <6) [27].
AR expression was analyzed using AR-antibody M3562 (DAKO) 1:100. The percentage of stained nuclei was scored and a value $>10 \%$ was considered positive [17].

Staining of GPER was performed using the GPER-antibody AF 5534 (R\&D System) 1:50 with confirmed specificity for GPER [30]. Total GPER staining was scored, according to a previous study from our group, as intensity at 5 levels ( 0 negative, 1 very weak, 2 weak, 3 moderate, and 4 strong) [29]. PM GPER staining was scored as the intensity at three levels ( 0 negative, 1 weak, and 2 strong). Level 1 to 2 were combined ending up with a binary variable (negative vs. positive).

ER (ER-alpha clone SP1, RM-9101 Thermo Scientific 1:200) and PR expression (Clone PgR636, M3569 DAKO $1: 100)$ were analyzed with IHC and a score of $\geq 1 \%$ stained nuclei was considered positive. PR expression was also analyzed with a $20 \%$ cut-off value for the luminal-like classification.

Ki67 (Clone MIB-1, M7240 DAKO 1:200) proliferation index was considered high if $\geq 24 \%$ cells were stained. The cut-off value was set at this level to mimic the fraction of high Ki67 tumors (7.8\%) in our previous whole tissue section analyses of ILC [37].

HER2 (CB11, Novocastra, 1:200) was categorized into four different IHC groups depending on the cell membrane staining intensity: $0,1+, 2+, 3+$. A value of IHC $3+$ was considered as HER2 positive. A HER2 gene amplification test was not performed.

\section{Luminal-like classification}

Based on the 2017 St Gallen luminal-like definitions [14], the tumors were divided into: luminal A-like (HER2-negative): grade $1+2$, low Ki67, and PR $>20 \%$ and luminal B-like (HER2-negative): at least one of the three criteria fulfilled: grade 3, high Ki67, or PR $\leq 20 \%$.

\section{Description of gene expression datasets}

In order to validate our IHC findings, we identified three independent publicly available gene expression ILC datasets [34-36].

The Metzger Filho et al. dataset [36] was downloaded from Gene Expression Omnibus (GEO) with accession number GSE88770, and was originally analyzed on the Affymetrix Human Genome U133 Plus 2.0 Array platform. It consists of 117 ILC tumors of which 100 where ER-positive/ HER2-negative, and primary endpoint was distant diseasefree survival (DDFS). Preprocessing of the data was made by the original authors.

The Michaut et al. [35] dataset was downloaded from GEO with accession number GSE68057, and data were originally obtained by an Agendia platform. It consists of 
Fig. 2 Representative images of immunohistochemical staining of AIB1, AR, and GPER: a AIB1 low (score 0) b AIB1: high (score 6) c AR negative $(\leq 10 \%)$ d AR positive $(>10 \%)$. e Total GPER negative (level 0) f Total GPER very weak (level 1) g Total GPER weak (level 2) h Total GPER moderate (level $3)$. None of the TMAs were classified as total GPER strong (level 4)
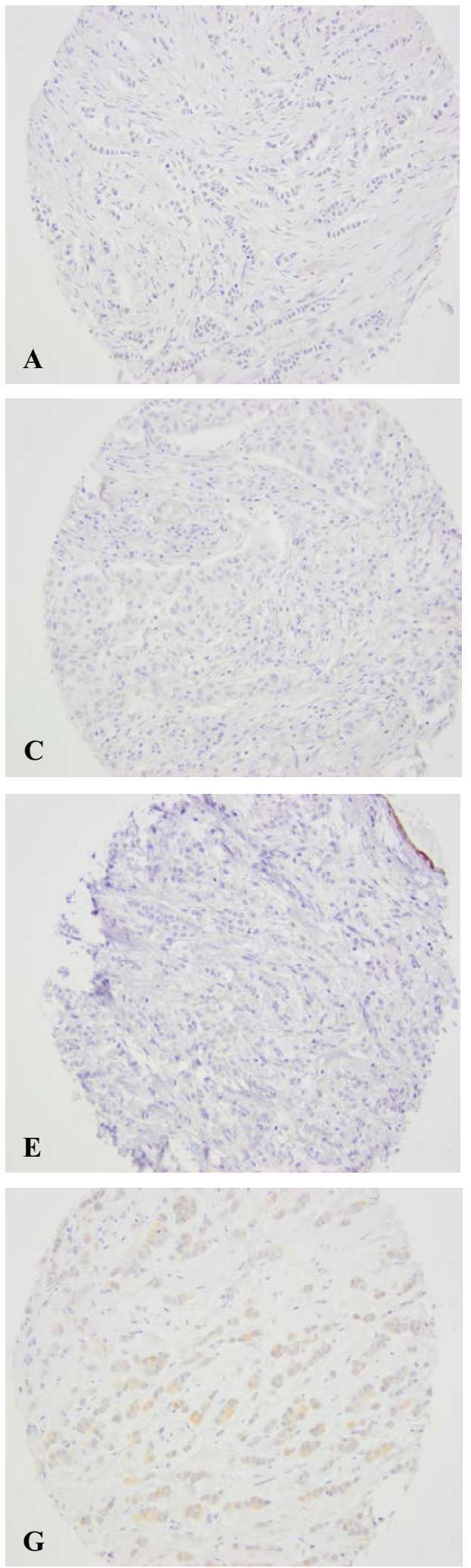
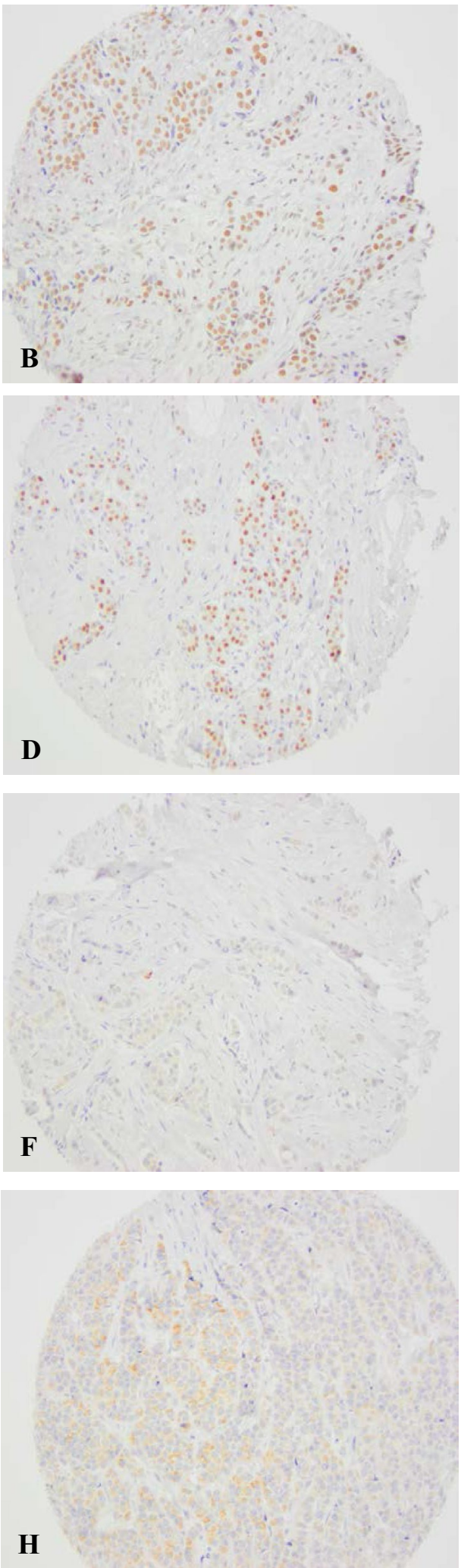

137 ILC tumors of which 108 where ER-positive/HER2negative, and primary endpoint was recurrence-free survival (RFS). The file marked as "processed data based on older annotations" was used, and patient data were downloaded directly from the publication website. Preprocessing of the data was made by the original authors. 
The METABRIC dataset [34] was downloaded from http://www.cBioPortal.org on 2018-01-15, and the datafile "data_expression" containing $\log 2$-transformed data was used. The original gene expression data were obtained by Illumina HT12 v3 microarray platform. The data were subset for ILC tumors. It consisted of 141 ILC tumors of which 123 where ER-positive/HER2-negative, and primary endpoint was overall survival (OS). Log intensity levels were used, as provided by the original authors.

No further preprocessing was done for the datasets, as we were interested in the relative gene expression levels within a cohort. Of note is the old annotations for some of the genes where GPER is also annotated as CMKRL2, and AIB1 is annotated as NCOA3. We have changed to a consistent use of gene symbols for clarity.

The cut-off values were set at levels to mimic the fractions of the concurrent IHC analyses in this study, and further statistical analysis was performed on the gene expression data in the same way as for the IHC data. [Distribution: 7\% high AIB1, 93\% AR positivity and total GPER: 0 (28\%); $1(42 \%) ; 2$ (29\%); 3 (1\%); and $4(0 \%)]$.

\section{Statistical analysis}

Associations between AIB1, AR, GPER, and other prognostic factors were assessed using Pearson's chi ${ }^{2}$ test. A trend version of this test, which is equivalent to a test for zero slope in a linear regression model, was used if one or both variables in a pair was ordinal with more than two categories (Table 3). The primary study endpoint was cumulative breast cancer mortality (BCM). For each patient, the FU time was counted from the date of surgery until death with or without breast cancer or, for the survivors, until June 2015. For the gene expression datasets, we used the same endpoints as originally published. The log-rank test was used to compare BCM, or other endpoints, in different strata (for variables with three or more ordered categories, a log-rank test for trend was used). Cause-specific Cox proportional hazards regression was used for estimation of hazard ratios (HR) which hence shall be interpreted as relative effects in a world where all other causes of death than breast cancer have been eliminated. Proportional hazard assumptions were checked graphically for each biomarker, and were found to be violated for, e.g., high vs. low AIB1 (Fig. 2). Hence, estimated HRs depend on FU time. Our pragmatic solution to this problem was to restrict the FU to the first 10 years. Complementary analyses with 25 years of FU were also performed to show how the estimated effects on BCM for the biomarkers level off with increased FU. These long-term effects should be cautiously interpreted as time averages. The FU exceeded 25 years for 42 patients, but since no breast cancer deaths occurred among them, this additional FU was not included when biomarker expression was analyzed in relation to BCM. All tests were twosided and the corresponding unadjusted $P$ values should be regarded as level of evidence against the null hypotheses tested. In the survival analyses, NHG, and nodal status were analyzed as factor variables on three levels, age as a continuous variable, and all other factors as dichotomous covariates. The statistical analysis software Stata version 15 (StataCorp, College Station, TX, USA) was used for statistical calculations.

The REMARK recommendations for reporting of tumor biomarker studies were followed [42].

\section{Results}

\section{Follow-up data}

Ninety-two patients $(41 \%)$ had a diagnosed recurrence at last FU, and the distribution of site of first recurrence was as follows: local in 23 patients, regional in 7, and distant in 62 . In addition, $23(10 \%)$ patients had developed a contralateral BC. At the end of the study, 66 patients (29\%) had died from breast cancer and 99 (44\%) from other causes. The remaining 59 patients (26\%) were still alive and had a median FU of 26 years (range $0.7-35$ years) in June 2015.

\section{AIB1, AR, and GPER and their associations to other prognostic factors}

Seven percent of the tumors were high-AIB1 (14/208) and 93\% were AR positive (183/196). For total GPER, most tumors were negatively stained (level $028 \%$ ) or showed very weak (level $142 \%$ ) and weak (level $229 \%$ ) staining intensity, whereas only three tumors had a moderate staining (level 3) and no tumor showed a strong staining (level 4) intensity. Based on these skewed total GPER distribution, we decided to combine level 2 to 4, resulting in analyses with three prognostic categories. Furthermore, with only four PM GPER-positive tumors, it was not meaningful to analyze this biomarker in relation to BCM (Table 2).

Positive associations were observed between GPER and both AIB1 $(P=0.01)$ and AR $(P=0.05)$. The evidence for a positive association between AIB1 and AR was weaker $(P=0.32)$. The associations between these three factors and other prognostic factors were also in general weak with strongest evidence for a positive association between AIB1 and Ki67 $(P=0.002)$ and for a negative association between AR expression and grade $(P<0.001)$ (Table 3). 
Table 2 Distribution of biomarkers and NHG

\begin{tabular}{|c|c|}
\hline Variables & No $(\%)$ \\
\hline \multicolumn{2}{|l|}{ PR } \\
\hline Positive $(\geq 1 \%)$ & $162(81)$ \\
\hline Negative $(<1 \%)$ & 37 (19) \\
\hline Missing & 25 \\
\hline \multicolumn{2}{|l|}{ Ki67 } \\
\hline Low $(<24 \%)$ & $182(92)$ \\
\hline High $(\geq 24 \%)$ & $15(8)$ \\
\hline Missing & 27 \\
\hline \multicolumn{2}{|l|}{ AIB1 } \\
\hline Low $($ score $<6)$ & $194(93)$ \\
\hline High (score 6) & $14(7)$ \\
\hline Missing & 16 \\
\hline \multicolumn{2}{|l|}{ GPER } \\
\hline Negative (0) & $59(28)$ \\
\hline Very weak (1) & $87(42)$ \\
\hline Weak (2) & $60(29)$ \\
\hline Moderate (3) & $3(1)$ \\
\hline Strong (4) & $0(0)$ \\
\hline Missing & 15 \\
\hline \multicolumn{2}{|l|}{ PM GPER } \\
\hline Positive $(1+2)$ & $4(2)$ \\
\hline Negative (0) & $205(98)$ \\
\hline Missing & 15 \\
\hline \multicolumn{2}{|l|}{ AR } \\
\hline Positive ( $>10 \%)$ & $183(93)$ \\
\hline Negative $(\leq 10 \%)$ & $13(7)$ \\
\hline Missing & 28 \\
\hline \multicolumn{2}{|l|}{ NHG } \\
\hline 1 & $28(14)$ \\
\hline 2 & $161(80)$ \\
\hline 3 & $13(6)$ \\
\hline Missing & 22 \\
\hline
\end{tabular}

$N H G$ Nottingham histological grade, $P R$ Progesterone receptor, Ki67 Proliferative fraction, GPER G protein-coupled estrogen receptor, $P M$ plasma membrane, $A R$ Androgen receptor

\section{Breast cancer mortality}

\section{Univariable analyses}

AIB1 (high vs. low) was associated with BCM with 10-year FU (HR 3.2, 95\% CI 1.4-7.8, $P=0.008$ ), but the effect and the evidence was weaker when analyzed with 25-year FU (HR 2.0, 95\% CI 0.87-4.8, $P=0.10$ ) (Fig. 3; Table 4). AR (positive vs. negative) showed a trend for a prognostic difference in BCM with 10-year FU (HR 0.56, 95\% CI 0.17-1.8), but the evidence was very weak $(P=0.33)$, and the effect was lost when analyzed with 25-year FU (HR 0.93, 95\% CI 0.29-3.0,

$P=0.90$ ) (Table 4; Online Resource 1). Total GPER (log-rank test for trend over the three observed categories) was neither associated with BCM with 10-year $(P=0.33)$ nor with 25 -year FU $(P=0.55)$. (Table 4; Online Resource 1) Ki67 (high vs. low) and NHG (3 vs. $1+2$ ) were prognostic for BCM with 10- and 25-year FU, whereas PR (positive vs. negative) was not (Table 4).

Sixty-five percent (125/193) of the evaluable tumors were classified as luminal A-like and the remaining as luminal B-like and the evidence for higher BCM in luminal B-like tumors was strong (10-year FU: HR 1.9, 95\% CI 1.1-3.1, $P=0.01 ;$ 25-year FU: HR 1.9, 95\% CI, 1.3-2.6 $P<0.001)$ (Online Resource 1).

\section{Multivariable analysis}

In a multivariable analysis adjusted for age, tumor size, nodal status, NHG, Ki67, luminal-like classification, and adjuvant systemic therapy (endocrine +/- chemo), AIB1 was associated with BCM with 10-year FU (HR 6.8, 95\% CI 2.3-20, $P=0.001)$. However, with longer follow-up, the independent AIB1 effect was found to level off (25-year FU: HR 3.0, 95\% CI $1.1-7.8, P=0.03)$.

\section{Analyses of gene expression data}

High AIB1 expression was associated with worse outcome (HR $>>1.00)$ in two out of the three datasets (METABRIC (HR 3.1, 95\% CI 1.3-7.4, $P=0.01$ ), Metzger Filho et al. (HR 3.6, 95\% CI 0.78-16, $P=0.10)$ ) (Fig. 4). High AR expression was associated with better outcome (HR $<<1.00)$ in two out of three datasets (Metzger Filho et al. (HR 0.24, 95\% CI $0.07-0.87, P=0.03$ ), Michaut et al. (HR 0.35, 95\% CI $0.08-1.6, P=0.18)$ ) (Online Resource 2). GPER was not associated with survival in any of the datasets (Online Resource 3).

\section{Discussion}

In this well-characterized case series of patients with ER-positive/HER2-negative ILC, a small subgroup of 14 patients (7\%) was found to have high expression of the estrogen receptor coactivator AIB1, and five of them died from breast cancer within approximately 5 years, translating to a high cumulative 5-year mortality in this subgroup compared to that in the large subgroup of patients with lower, or no, expression of AIB1 (Fig. 2). However, no late breast cancer deaths were registered in this group with six patients surviving more than 10 years and three more than 25 years. Hence, the estimated mortality ratio for AIB1 (high vs. low) was strongly dependent on FU time. In univariable analysis, it was estimated to 3.2 and 2.0 with FU of 10 and 25 years, respectively. Furthermore, the uncertainty in the estimated 
Table 3 Association between AR, AIB1, GPER, and other prognostic factors ${ }^{\mathrm{a}}$

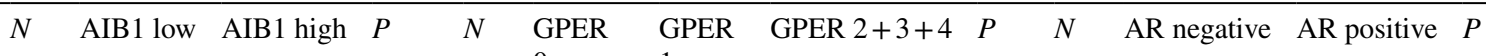
$0 \quad 1$

\begin{tabular}{|c|c|c|c|c|c|c|c|c|c|c|c|c|c|}
\hline \multicolumn{14}{|l|}{ Nodal status } \\
\hline 0 & 122 & $114(62)$ & $8(57)$ & 0.56 & 120 & $32(57)$ & 48 (59) & $40(66)$ & 0.43 & 114 & $6(50)$ & $108(62)$ & 0.27 \\
\hline $1-3$ & 35 & $33(18)$ & $2(14)$ & & 36 & $11(20)$ & $16(20)$ & $9(15)$ & & 36 & $2(17)$ & $34(19)$ & \\
\hline $4+$ & 41 & $37(20)$ & $4(29)$ & & 43 & $13(23)$ & $18(22)$ & $12(20)$ & & 37 & $4(33)$ & $33(19)$ & \\
\hline No & 122 & $114(62)$ & $8(57)$ & 0.72 & 120 & $32(57)$ & $48(59)$ & $40(66)$ & 0.35 & 114 & $6(50)$ & $108(62)$ & 0.42 \\
\hline$N+$ & 76 & $70(38)$ & $6(43)$ & & 79 & $24(43)$ & $34(41)$ & $21(34)$ & & 73 & $6(50)$ & $67(38)$ & \\
\hline \multicolumn{14}{|l|}{ Size } \\
\hline $0-20 \mathrm{~mm}$ & 116 & $106(55)$ & $10(77)$ & 0.13 & 116 & $28(47)$ & $56(66)$ & $32(52)$ & 0.67 & 107 & $4(31)$ & $103(57)$ & 0.06 \\
\hline$>20 \mathrm{~mm}$ & 89 & $86(45)$ & $3(23)$ & & 90 & $31(53)$ & $29(34)$ & $30(48)$ & & 86 & $9(69)$ & $77(43)$ & \\
\hline \multicolumn{14}{|l|}{ Menopause } \\
\hline Pre & 50 & $47(25)$ & $3(21)$ & & 50 & $17(29)$ & $22(27)$ & $11(17)$ & & 45 & $3(23)$ & $42(24)$ & \\
\hline Post & 151 & $140(75)$ & $11(79)$ & 0.10 & 152 & $41(71)$ & $59(73)$ & $52(83)$ & 0.13 & 145 & $10(77)$ & $135(76)$ & 0.96 \\
\hline \multicolumn{14}{|l|}{ NHG } \\
\hline 1 & 23 & $21(12)$ & $2(15)$ & 0.39 & 24 & $5(9)$ & $14(18)$ & $5(9)$ & 0.81 & 23 & $0(0)$ & $23(14)$ & $<0.001$ \\
\hline 2 & 152 & $141(81)$ & $11(85)$ & & 152 & $45(83)$ & $61(77)$ & $46(82)$ & & 142 & $7(58)$ & $135(81)$ & \\
\hline 3 & 13 & $13(7)$ & 0 & & 13 & $4(7)$ & $4(5)$ & $5(9)$ & & 13 & $5(42)$ & $8(5)$ & \\
\hline $1+2$ & 175 & $162(93)$ & $13(100)$ & 0.31 & 176 & $50(93)$ & 75 (95) & $51(91)$ & 0.75 & 165 & $7(58)$ & $158(95)$ & $<0.001$ \\
\hline 3 & 13 & $13(7)$ & 0 & & 13 & $4(7)$ & $4(5)$ & $5(9)$ & & 13 & $5(42)$ & $8(5)$ & \\
\hline \multicolumn{14}{|l|}{ PR } \\
\hline$<1 \%$ & 34 & $31(17)$ & $3(21)$ & 0.68 & 37 & $11(20)$ & $14(17)$ & $12(20)$ & 0.95 & 35 & $2(15)$ & $33(19)$ & 0.76 \\
\hline$\geq 1 \%$ & 161 & $150(83)$ & $11(79)$ & & 161 & $44(80)$ & $70(83)$ & $47(80)$ & & 154 & $11(85)$ & $143(81)$ & \\
\hline \multicolumn{14}{|l|}{ Ki67 } \\
\hline Low & 180 & $170(94)$ & $10(71)$ & 0.002 & 182 & $53(96)$ & $76(92)$ & $53(90)$ & 0.19 & 176 & $11(85)$ & $165(93)$ & 0.25 \\
\hline High & 15 & $11(6)$ & 4 (29) & & 15 & $2(4)$ & $7(8)$ & $6(10)$ & & 14 & $2(15)$ & $12(7)$ & \\
\hline \multicolumn{14}{|l|}{ AIB1 } \\
\hline Low & & & & & 190 & $57(100)$ & 79 (92) & $54(89)$ & 0.01 & 13 & $0(0)$ & $13(7)$ & 0.32 \\
\hline High & & & & & 14 & 0 & $7(8)$ & $7(11)$ & & 180 & $13(100)$ & $167(93)$ & \\
\hline \multicolumn{14}{|l|}{ GPER } \\
\hline 0 & & & & & & & & & & 57 & $8(62)$ & $49(27)$ & 0.05 \\
\hline 1 & & & & & & & & & & 77 & $2(15)$ & $75(41)$ & \\
\hline $2+3+4$ & & & & & & & & & & 61 & $3(23)$ & $58(32)$ & \\
\hline
\end{tabular}

${ }^{a}$ For 2-by-2-tables, $P$ values were calculated using Pearson's chi2 test. For larger tables, where at least one variable is ordinal with $>2$ categories, a trend version of this test was used. The latter test is equivalent to a test for zero slope in a linear regression model

cumulative BCM for high-AIB1 is large for this group compared to low-AIB1, as reflected by the shaded $95 \%$ pointwise confidence bands in Fig. 2. Nevertheless, with 10-year FU, AIB1 was found to be an independent prognostic factor for BCM after adjustment for age, tumor size, nodal status, NHG, Ki67, luminal-like classification, and adjuvant systemic therapy.

Forty-one percent developed a loco-, regional-, or distant recurrence, as compared to $29 \% \mathrm{BC}$ deaths from BC. Considering this, a complementary analysis was made, exploring the association between AIB1 and recurrence, and essentially the same prognostic effect of AIB1 was seen for the endpoint recurrence-free interval [43] (data not shown).
The association between high-AIB1 and poor prognosis is in agreement with previous BC studies from our group (including NST) [23, 24, 27], but the percentage of tumors with high-AIB1 was found to be lower in this ILC cohort. Results from an exploratory analysis with further subdivision of AIB1 into low $<5(N=98)$, intermediate 5-5.5 $(N=96)$, and high $6(N=14)$, were in concert with previous studies from our group [24, 27], and showed no difference in clinical outcome between the low and intermediate groups (data not shown). These findings support the choice of score 6 as an appropriate cut-off value in the present study. Further larger studies are warranted in order to find the most optimal cut-off for AIB1 in ER-positive/HER2-negative ILC. 


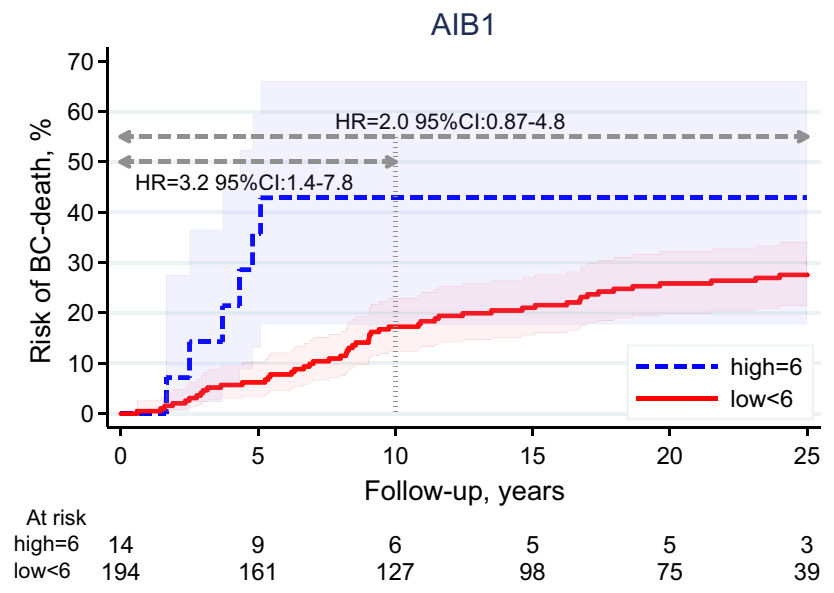

Fig. 3 AIB1: Breast cancer mortality (10- and 25-year FU)

In line with other studies, AIB1 was also associated with high Ki67 [27] but in contrast, AIB1 was not associated with NHG 3. As expected, only a small fraction of the ILCs were classified as NHG $3(N=13)$, and furthermore, none of them had high AIB1 expression.

In addition to AIB1, we studied the prognostic importance of AR and GPER, but without finding any significant results associated with outcome for these two endocrine biomarkers. The skewed distribution of both AR (only 7\% AR negative) and GPER (only $1 \%$ of the tumors showed a moderate/strong total GPER staining and only $2 \%$ were GPER positive in the plasma membrane) reduces the power to detect prognostic effects.

The low fraction of tumors, with a high total GPER/PM GPER positivity in ILC, are in contrast to previous results on ER-positive BC (including NST) from our group [29, 30], and may indicate a subtype-specific difference compared to NST.

Results from analyses of the publicly available gene expression ILC datasets strengthened our IHC findings for AIB1. High expression of AIB1 was a negative prognostic factor in two out of three datasets (HR 3.1 and HR 3.6, respectively). The evidence for association between
Table 4 Univariable analysis of breast cancer mortality (10- and 25-year FU) in invasive lobular carcinoma

\begin{tabular}{|c|c|c|c|c|c|c|c|}
\hline & \multirow[t]{2}{*}{$N$} & \multicolumn{3}{|c|}{ 10-year FU } & \multicolumn{3}{|c|}{ 25-year FU } \\
\hline & & HR & $95 \% \mathrm{CI}$ & $P$ value & HR & $95 \% \mathrm{CI}$ & $P$ value \\
\hline Age (years) & 224 & 0.95 & $0.93-0.98$ & 0.001 & 0.97 & $0.95-0.99$ & 0.01 \\
\hline \multicolumn{8}{|l|}{ Tumor size (mm) } \\
\hline$\leq 20$ & 125 & 1.0 & & & 1.0 & & \\
\hline$>20$ & 96 & 4.1 & $2.1-7.8$ & $<0.001$ & 3.5 & $2.1-5.7$ & $<0.001$ \\
\hline \multicolumn{8}{|l|}{ Nodal status $(P<0.001)^{\mathrm{a}}$} \\
\hline $0+$ & 129 & 1.0 & & & 1.0 & & \\
\hline $1-3+$ & 40 & 1.7 & $0.74-4.1$ & 0.20 & 1.2 & $0.62-2.5$ & 0.54 \\
\hline$>3+$ & 44 & 5.6 & $2.0-11$ & $<0.001$ & 3.5 & $2.0-6.0$ & $<0.001$ \\
\hline \multicolumn{8}{|l|}{ Histological grade } \\
\hline $1+2$ & 189 & 1.0 & & & 1.0 & & \\
\hline 3 & 13 & 4.1 & $1.6-10$ & 0.003 & 3.8 & $1.6-8.8$ & 0.002 \\
\hline \multicolumn{8}{|l|}{ PR } \\
\hline$+(\geq 1 \%)$ & 162 & 1.0 & & 0.29 & 1.0 & & \\
\hline$-(<1 \%)$ & 37 & 1.5 & $0.71-3.2$ & & 1.4 & $0.71-2.6$ & 0.33 \\
\hline \multicolumn{8}{|l|}{ Ki67 } \\
\hline $0-23 \%$ & 182 & 1.0 & & & 1.0 & & \\
\hline$\geq 24 \%$ & 15 & 4.9 & $2.2-11$ & $<0.001$ & 5.9 & $3.1-11$ & $<0.001$ \\
\hline \multicolumn{8}{|l|}{ AIB1 } \\
\hline Low + medium $($ score $<6)$ & 194 & 1.0 & & & 1.0 & & \\
\hline High (score 6) & 14 & 3.2 & $1.4-7.8$ & 0.008 & 2.0 & $0.87-4.8$ & 0.10 \\
\hline \multicolumn{8}{|l|}{$\operatorname{GPER}(P=0.38)^{\mathrm{a}}$} \\
\hline Negative (0) & 59 & 1.0 & & & 1.0 & & \\
\hline Very weak (1) & 87 & 0.79 & $0.38-1.6$ & 0.54 & 0.86 & $0.47-1.6$ & 0.62 \\
\hline Weak + moderate + strong $(2-4)$ & 63 & 0.69 & $0.300-1.6$ & 0.38 & 0.87 & $0.45-1.7$ & 0.69 \\
\hline \multicolumn{8}{|l|}{$\mathrm{AR}$} \\
\hline$+(>10 \%)$ & 183 & 1.0 & & & 1.0 & & \\
\hline$-(\leq 10 \%)$ & 13 & 1.8 & $0.56-5.9$ & 0.33 & 1.1 & $0.34-3.5$ & 0.90 \\
\hline
\end{tabular}

${ }^{\text {a } L o g-r a n k ~ t e s t ~ f o r ~ t r e n d ~}$ 

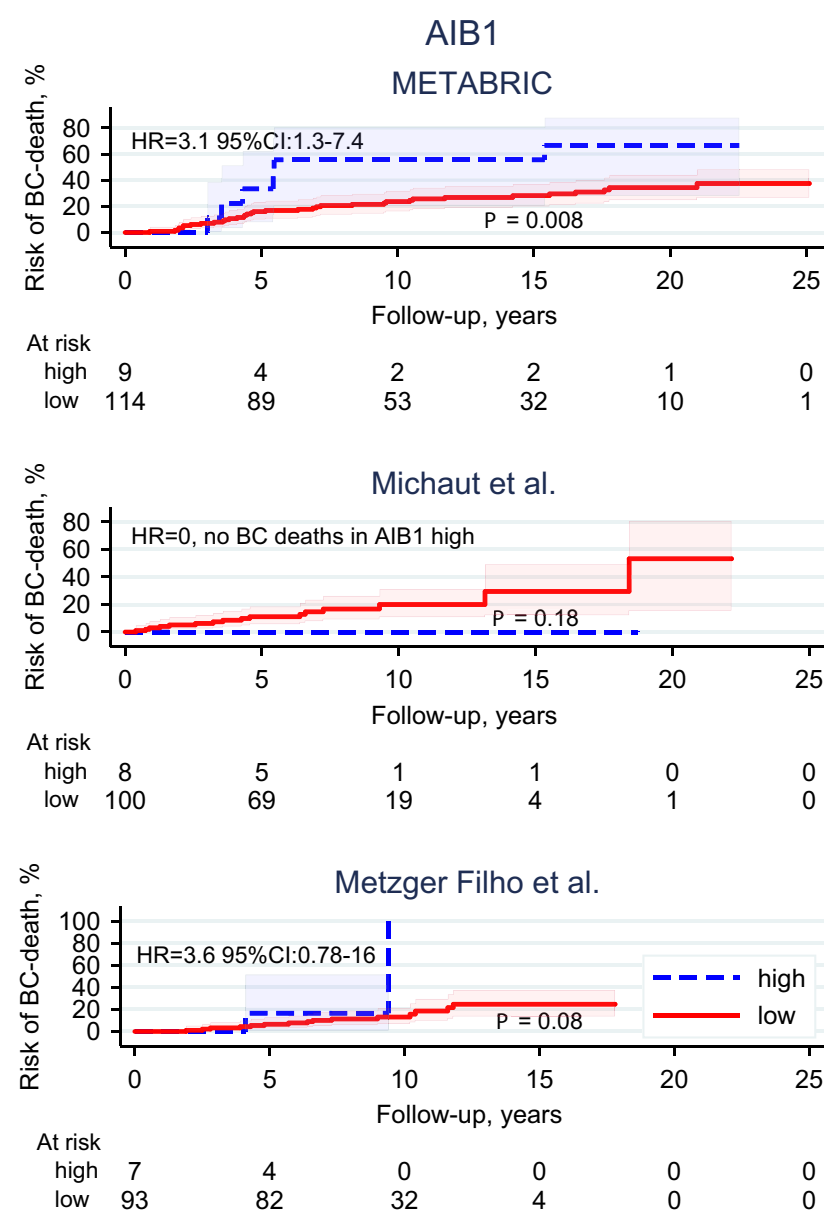

Fig. 4 AIB1: Risk of breast cancer death assessed by gene expression data in three independent publicly available datasets of invasive lobular carcinoma ( $P$ value: log-rank test)

high-AIB1 and worse outcome in these datasets was, however, modest ( $P=0.01$ and $P=0.10$, respectively).

As expected, we also found that Ki67, NHG, and the luminal-like classification were prognostic, and the same trends could be identified in the gene expression ILC datasets (data not shown).

One of the strengths of the present study is the reevaluation of histological type by clinical pathologists specialized in breast pathology. Another is the long FU time (median 26 years), since the lobular subtype, with a high proportion of luminal A-like tumors, are associated with an increased risk of late recurrences (e.g., in this cohort, 21 out of 66 breast cancer deaths occurred $\geq 10$ years after diagnosis).

The study also has limitations. Besides the limited number of patients and the skewed distribution of the experimental biomarkers, one might also argue that TMAs are not optimal for IHC evaluation of biomarkers in ILC, with a scattered growth pattern characterized by single-file infiltrating cells. However, when comparing the present results for ER, PR, and Ki67, analyzed on TMA, with the previous study from our group, using whole tissue sections instead, essentially the same results were obtained for prognostic considerations.

The majority of the patients (58\%) in this study did not receive any adjuvant systemic therapy. Most of the patients with endocrine treatment received tamoxifen for 2 years and only $2 \%$ received chemotherapy. Furthermore, if adjuvant systemic therapy (endocrine $+/$ - chemo) had been given in accordance with current treatment guidelines, the BCM in this ILC cohort would probably have been lower, and some of the very late recurrences ( $\geq 10$ year past diagnosis) could potentially have been avoided.

In conclusion, this retrospective study shows prognostic value of AIB1 in ER-positive/HER2-negative ILC both when assessed by immunohistochemistry and by gene expression assays. Validation of this finding in independent cohorts is warranted.

Acknowledgements We thank Ingrid Idvall and Poul Boiesen for the pathological reevaluation of histological type, and Dorthe Grabau and Anna Ehinger for the histological grading.

Funding This study was funded by the Swedish Breast Cancer Association (BRO), the Cancer Foundation Kronoberg, Kronoberg County Council's Research and Development Foundation, the Swedish Cancer Society, the Faculty of Medicine at Lund University, the Lund University Research Foundation, the Gunnar Nilsson Cancer Foundation, the Anna and Edwin Berger Foundation, the Swedish Cancer and Allergy Foundation, Skåne County Council's Research and Development Foundation, the Mrs. Berta Kamprad Research Foundation, Governmental Funding of Research within the National Health Service (ALF), the Swedish Cancer Foundation (CAN 2016/423), and the Swedish Research Council (2016-02427).

\section{Compliance with ethical standards}

Conflict of interest The authors declare that they have no conflict of interest.

Ethical approval The study was approved by the Regional Ethical Review Board (EPN) at Lund University, Lund, Sweden (LU 240-01 and LU 2015/102).

Open Access This article is distributed under the terms of the Creative Commons Attribution 4.0 International License (http://creativeco mmons.org/licenses/by/4.0/), which permits unrestricted use, distribution, and reproduction in any medium, provided you give appropriate credit to the original author(s) and the source, provide a link to the Creative Commons license, and indicate if changes were made.

\section{References}

1. Garcia-Fernandez A, Lain JM, Chabrera C, Garcia Font M, Fraile M, Barco I, Torras M, Rene A, Gonzalez S, Gonzalez C, Piqueras M, Veloso E, Cirera L, Pessarrodona A, Gimenez N (2015) Comparative Long-term Study of a Large Series of Patients with Invasive Ductal Carcinoma and Invasive Lobular Carcinoma. 
Loco-Regional Recurrence, Metastasis, and Survival. Breast J 21(5):533-537. https://doi.org/10.1111/tbj.12455

2. Rakha EA, Gill MS, El-Sayed ME, Khan MM, Hodi Z, Blamey RW, Evans AJ, Lee AH, Ellis IO (2009) The biological and clinical characteristics of breast carcinoma with mixed ductal and lobular morphology. Breast Cancer Res Treat 114(2):243-250. https://doi.org/10.1007/s10549-008-0007-4

3. Lakhani SR, Ellis IO, Schnitt SJ, Tan PH, van de Vijver MJ (eds) (2012) WHO Classification of Tumours of the Breast. 4th Edn. WHO press

4. Martinez V, Azzopardi JG (1979) Invasive lobular carcinoma of the breast: incidence and variants. Histopathology 3(6):467-488

5. Acs G, Lawton TJ, Rebbeck TR, LiVolsi VA, Zhang PJ (2001) Differential expression of E-cadherin in lobular and ductal neoplasms of the breast and its biologic and diagnostic implications. Am J Clin Pathol 115(1):85-98. https://doi.org/10.1309/ FDHX-L92R-BATQ-2GE0

6. Arpino G, Bardou VJ, Clark GM, Elledge RM (2004) Infiltrating lobular carcinoma of the breast: tumor characteristics and clinical outcome. Breast Cancer Res 6(3):R149-R156. https:// doi.org/10.1186/bcr767

7. Wasif N, Maggard MA, Ko CY, Giuliano AE (2010) Invasive lobular vs. ductal breast cancer: a stage-matched comparison of outcomes. Ann Surg Oncol 17(7):1862-1869. https://doi. org/10.1245/s10434-010-0953-Z

8. Barroso-Sousa R, Metzger-Filho O (2016) Differences between invasive lobular and invasive ductal carcinoma of the breast: results and therapeutic implications. Ther Adv Med Oncol 8(4):261-266. https://doi.org/10.1177/1758834016644156

9. Ciriello G, Gatza ML, Beck AH, Wilkerson MD, Rhie SK, Pastore A, Zhang H, McLellan M, Yau C, Kandoth C, Bowlby R, Shen H, Hayat S, Fieldhouse R, Lester SC, Tse GM, Factor RE, Collins LC, Allison KH, Chen YY, Jensen K, Johnson NB, Oesterreich S, Mills GB, Cherniack AD, Robertson G, Benz C, Sander C, Laird PW, Hoadley KA, King TA, Network TR, Perou CM (2015) Comprehensive Molecular Portraits of Invasive Lobular Breast Cancer. Cell 163(2):506-519. https://doi.org/10.1016/j.cell.2015.09.033

10. Desmedt C, Zoppoli G, Sotiriou C, Salgado R (2017) Transcriptomic and genomic features of invasive lobular breast cancer. Semin Cancer Biol. https://doi.org/10.1016/j.semca ncer.2017.03.007

11. Cristofanilli M, Gonzalez-Angulo A, Sneige N, Kau SW, Broglio K, Theriault RL, Valero V, Buzdar AU, Kuerer H, Buccholz TA, Hortobagyi GN (2005) Invasive lobular carcinoma classic type: response to primary chemotherapy and survival outcomes. J Clin Oncol 23(1):41-48. https://doi.org/10.1200/JCO.2005.03.111

12. Rakha EA, El-Sayed ME, Powe DG, Green AR, Habashy H, Grainge MJ, Robertson JF, Blamey R, Gee J, Nicholson RI, Lee $\mathrm{AH}$, Ellis IO (2008) Invasive lobular carcinoma of the breast: response to hormonal therapy and outcomes. Eur J Cancer 44(1):73-83. https://doi.org/10.1016/j.ejca.2007.10.009

13. Pestalozzi BC, Zahrieh D, Mallon E, Gusterson BA, Price KN, Gelber RD, Holmberg SB, Lindtner J, Snyder R, Thurlimann B, Murray E, Viale G, Castiglione-Gertsch M, Coates AS, Goldhirsch A (2008) Distinct clinical and prognostic features of infiltrating lobular carcinoma of the breast: combined results of 15 International Breast Cancer Study Group clinical trials. J Clin Oncol 26(18):3006-3014. https://doi.org/10.1200/ JCO.2007.14.9336

14. Curigliano G, Burstein HJ, Gnant EPW, Dubsky M, Loibl P, Colleoni S, Regan M, Piccart-Gebhart MM, Senn M, Thurlimann HJ, B, St. Gallen International Expert Consensus on the Primary Therapy of Early Breast, Andre C, Baselga F, Bergh J, Bonnefoi J, Cardoso HSYB, Carey F, Ciruelos L, Cuzick E, Denkert J, Di Leo C, Ejlertsen A, Francis B, Galimberti P, Garber V, Gulluoglu J, Goodwin B, Harbeck P, Hayes N, Huang DF,
Huober CS, Hussein J, Jassem K, Jiang J, Karlsson Z, Morrow P, Orecchia M, Osborne R, Pagani KC, Partridge O, Pritchard AH, Ro K, Rutgers J, Sedlmayer EJT, Semiglazov F, Shao V, Smith Z, Toi I, Tutt M, Viale A, Watanabe G, Whelan T, Xu TJB (2017) De-escalating and escalating treatments for earlystage breast cancer: the St. Gallen International Expert Consensus Conference on the Primary Therapy of Early Breast Cancer 2017. Ann Oncol 28(8):1700-1712. https://doi.org/10.1093/ annonc/mdx 308

15. Riva C, Dainese E, Caprara G, Rocca PC, Massarelli G, Tot T, Capella C, Eusebi V (2005) Immunohistochemical study of androgen receptors in breast carcinoma. Evidence of their frequent expression in lobular carcinoma. Virchows Arch 447(4):695-700. https://doi.org/10.1007/s00428-005-0003-6

16. Moinfar F, Okcu M, Tsybrovskyy O, Regitnig P, Lax SF, Weybora W, Ratschek M, Tavassoli FA, Denk H (2003) Androgen receptors frequently are expressed in breast carcinomas: potential relevance to new therapeutic strategies. Cancer 98(4):703-711. https://doi. org/10.1002/cncr. 11532

17. Vera-Badillo FE, Templeton AJ, de Gouveia P, Diaz-Padilla I, Bedard PL, Al-Mubarak M, Seruga B, Tannock IF, Ocana A, Amir E (2014) Androgen receptor expression and outcomes in early breast cancer: a systematic review and meta-analysis. J Natl Cancer Inst 106(1):djt319. https://doi.org/10.1093/jnci/djt319

18. Aleskandarany MA, Abduljabbar R, Ashankyty I, Elmouna A, Jerjees D, Ali S, Buluwela L, Diez-Rodriguez M, Caldas C, Green AR, Ellis IO, Rakha EA (2016) Prognostic significance of androgen receptor expression in invasive breast cancer: transcriptomic and protein expression analysis. Breast Cancer Res Treat 159(2):215-227. https://doi.org/10.1007/s10549-016-3934-5

19. Bozovic-Spasojevic I, Zardavas D, Brohee S, Ameye L, Fumagalli D, Ades F, de Azambuja E, Bareche Y, Piccart M, Paesmans M, Sotiriou C (2017) The prognostic role of androgen receptor in patients with early-stage breast cancer: A meta-analysis of clinical and gene expression data. Clin Cancer Res 23(11):2702-2712. https://doi.org/10.1158/1078-0432.CCR-16-0979

20. Carreno G, Del Casar JM, Corte MD, Gonzalez LO, Bongera M, Merino AM, Juan G, Obregon R, Martinez E, Vizoso FJ (2007) Local recurrence after mastectomy for breast cancer: analysis of clinicopathological, biological and prognostic characteristics. Breast Cancer Res Treat 102(1):61-73. https://doi.org/10.1007/ s10549-006-9310-0

21. Lakis S, Kotoula V, Eleftheraki AG, Batistatou A, Bobos M, Koletsa T, Timotheadou E, Chrisafi S, Pentheroudakis G, Koutras A, Zagouri F, Linardou H, Fountzilas G (2014) The androgen receptor as a surrogate marker for molecular apocrine breast cancer subtyping. Breast 23(3):234-243. https://doi.org/10.1016/j. breast.2014.02.013

22. Lee K, Lee A, Song BJ, Kang CS (2011) Expression of AIB1 protein as a prognostic factor in breast cancer. World J Surg Oncol 9:139. https://doi.org/10.1186/1477-7819-9-139

23. Alkner S, Bendahl PO, Grabau D, Lovgren K, Stal O, Ryden L, Ferno M (2010) AIB1 is a predictive factor for tamoxifen response in premenopausal women. Ann Oncol 21(2):238-244. https://doi. org/10.1093/annonc/mdp293

24. Alkner S, Jensen MB, Rasmussen BB, Bendahl PO, Ferno M, Ryden L, Mouridsen H, Danish Breast Cancer Cooperative G (2017) Prognostic and predictive importance of the estrogen receptor coactivator AIB1 in a randomized trial comparing adjuvant letrozole and tamoxifen therapy in postmenopausal breast cancer: the Danish cohort of BIG 1-98. Breast Cancer Res Treat. https://doi.org/10.1007/s1054 9-017-4416-0

25. Chang AK, Wu H (2012) The role of AIB1 in breast cancer. Oncol Lett 4(4):588-594. https://doi.org/10.3892/ol.2012.803

26. Osborne CK, Bardou V, Hopp TA, Chamness GC, Hilsenbeck SG, Fuqua SA, Wong J, Allred DC, Clark GM, Schiff R (2003) Role 
of the estrogen receptor coactivator AIB1 (SRC-3) and HER-2/ neu in tamoxifen resistance in breast cancer. J Natl Cancer Inst 95(5):353-361

27. Alkner S, Bendahl PO, Ehinger A, Lovgren K, Ryden L, Ferno M (2016) Prior adjuvant tamoxifen treatment in breast cancer Is linked to increased AIB1 and HER2 expression in metachronous contralateral breast cancer. PLoS ONE 11(3):e0150977. https://doi. org/10.1371/journal.pone.0150977

28. Weiner M, Skoog L, Fornander T, Nordenskjold B, Sgroi DC, Stal O (2013) Oestrogen receptor co-activator AIB1 is a marker of tamoxifen benefit in postmenopausal breast cancer. Ann Oncol 24(8):1994-1999. https://doi.org/10.1093/annonc/mdt159

29. Sjostrom M, Hartman L, Grabau D, Fornander T, Malmstrom P, Nordenskjold B, Sgroi DC, Skoog L, Stal O, Leeb-Lundberg LM, Ferno M (2014) Lack of G protein-coupled estrogen receptor (GPER) in the plasma membrane is associated with excellent longterm prognosis in breast cancer. Breast Cancer Res Treat 145(1):6171. https://doi.org/10.1007/s10549-014-2936-4

30. Broselid S, Cheng B, Sjostrom M, Lovgren K, Klug-De Santiago HL, Belting M, Jirstrom K, Malmstrom P, Olde B, Bendahl PO, Hartman L, Ferno M, Leeb-Lundberg LM (2013) G protein-coupled estrogen receptor is apoptotic and correlates with increased distant disease-free survival of estrogen receptor-positive breast cancer patients. Clin Cancer Res 19(7):1681-1692. https://doi. org/10.1158/1078-0432.CCR-12-2376

31. Ignatov T, Weissenborn C, Poehlmann A, Lemke A, Semczuk A, Roessner A, Costa SD, Kalinski T, Ignatov A (2013) GPER-1 expression decreases during breast cancer tumorigenesis. Cancer Invest 31(5):309-315. https://doi.org/10.3109/07357 907.2013.789901

32. Filardo EJ, Graeber CT, Quinn JA, Resnick MB, Giri D, DeLellis RA, Steinhoff MM, Sabo E (2006) Distribution of GPR30, a seven membrane-spanning estrogen receptor, in primary breast cancer and its association with clinicopathologic determinants of tumor progression. Clin Cancer Res 12(21):6359-6366. https://doi. org/10.1158/1078-0432.CCR-06-0860

33. Kuo WH, Chang LY, Liu DL, Hwa HL, Lin JJ, Lee PH, Chen CN, Lien HC, Yuan RH, Shun CT, Chang KJ, Hsieh FJ (2007) The interactions between GPR30 and the major biomarkers in infiltrating ductal carcinoma of the breast in an Asian population. Taiwan J Obstet Gynecol 46(2):135-145. https://doi.org/10.1016/S1028 $-4559(07) 60007-2$

34. Curtis C, Shah SP, Chin SF, Turashvili G, Rueda OM, Dunning MJ, Speed D, Lynch AG, Samarajiwa S, Yuan Y, Graf S, Ha G, Haffari G, Bashashati A, Russell R, McKinney S, Group M, Langerod A, Green A, Provenzano E, Wishart G, Pinder S, Watson P, Markowetz F, Murphy L, Ellis I, Purushotham A, Borresen-Dale AL, Brenton JD, Tavare S, Caldas C, Aparicio S (2012) The genomic and transcriptomic architecture of 2,000 breast tumours reveals novel subgroups. Nature 486(7403):346-352. https://doi.org/10.1038/natur e10983

35. Michaut M, Chin SF, Majewski I, Severson TM, Bismeijer T, de Koning L, Peeters JK, Schouten PC, Rueda OM, Bosma AJ, Tarrant F, Fan Y, He B, Xue Z, Mittempergher L, Kluin RJ, Heijmans J, Snel M, Pereira B, Schlicker A, Provenzano E, Ali HR, Gaber A, O’Hurley G, Lehn S, Muris JJ, Wesseling J, Kay E, Sammut SJ, Bardwell HA, Barbet AS, Bard F, Lecerf C, O'Connor DP, Vis
DJ, Benes CH, McDermott U, Garnett MJ, Simon IM, Jirstrom K, Dubois T, Linn SC, Gallagher WM, Wessels LF, Caldas C, Bernards $\mathrm{R}$ (2016) Integration of genomic, transcriptomic and proteomic data identifies two biologically distinct subtypes of invasive lobular breast cancer. Sci Rep 6:18517. https://doi.org/10.1038/srep18517

36. Metzger-Filho O, Michiels S, Bertucci F, Catteau A, Salgado R, Galant C, Fumagalli D, Singhal SK, Desmedt C, Ignatiadis M, Haussy S, Finetti P, Birnbaum D, Saini KS, Berliere M, Veys I, de Azambuja E, Bozovic I, Peyro-Saint-Paul H, Larsimont D, Piccart M, Sotiriou C (2013) Genomic grade adds prognostic value in invasive lobular carcinoma. Ann Oncol 24(2):377-384. https://doi.org/10.1093/ annonc/mds 280

37. Narbe U, Bendahl PO, Grabau D, Ryden L, Ingvar C, Ferno M (2014) Invasive lobular carcinoma of the breast: long-term prognostic value of Ki67 and histological grade, alone and in combination with estrogen receptor. Springerplus 3:70. https://doi. org/10.1186/2193-1801-3-70

38. Elston CW, Ellis IO (1991) Pathological prognostic factors in breast cancer. I. The value of histological grade in breast cancer: experience from a large study with long-term follow-up. Histopathology 19(5):403-410

39. Dihge L, Bendahl PO, Grabau D, Isola J, Lovgren K, Ryden L, Ferno M (2008) Epidermal growth factor receptor (EGFR) and the estrogen receptor modulator amplified in breast cancer (AIB1) for predicting clinical outcome after adjuvant tamoxifen in breast cancer. Breast Cancer Res Treat 109(2):255-262. https://doi.org/10.1007/ s10549-007-9645-1

40. List HJ, Reiter R, Singh B, Wellstein A, Riegel AT (2001) Expression of the nuclear coactivator AIB1 in normal and malignant breast tissue. Breast Cancer Res Treat 68(1):21-28

41. Kirkegaard T, McGlynn LM, Campbell FM, Muller S, Tovey SM, Dunne B, Nielsen KV, Cooke TG, Bartlett JM (2007) Amplified in breast cancer 1 in human epidermal growth factor receptor - positive tumors of tamoxifen-treated breast cancer patients. Clin Cancer Res 13(5):1405-1411. https://doi.org/10.1158/1078-0432.CCR-06-1933

42. McShane LM, Altman DG, Sauerbrei W, Taube SE, Gion M, Clark GM (2006) REporting recommendations for tumor MARKer prognostic studies (REMARK). Breast Cancer Res Treat 100(2):229 235. https://doi.org/10.1007/s10549-006-9242-8

43. Gourgou-Bourgade S, Cameron D, Poortmans P, Asselain B, Azria D, Cardoso F, A'Hern R, Bliss J, Bogaerts J, Bonnefoi H, Brain E, Cardoso MJ, Chibaudel B, Coleman R, Cufer T, Dal Lago L, Dalenc F, De Azambuja E, Debled M, Delaloge S, Filleron T, Gligorov J, Gutowski M, Jacot W, Kirkove C, MacGrogan G, Michiels S, Negreiros I, Offersen BV, Penault Llorca F, Pruneri G, Roche H, Russell NS, Schmitt F, Servent V, Thurlimann B, Untch M, van der Hage JA, van Tienhoven G, Wildiers H, Yarnold J, Bonnetain F, Mathoulin-Pelissier S, Bellera C, Dabakuyo-Yonli TS, Definition for the Assessment of Time-to-event Endpoints in Cancer Trials I (2015) Guidelines for time-to-event end point definitions in breast cancer trials: results of the DATECAN initiative (Definition for the Assessment of Time-to-event Endpoints in CANcer trials)dagger. Ann Oncol 26(5):873-879. https://doi.org/10.1093/annonc/mdv106

Publisher's Note Springer Nature remains neutral with regard to jurisdictional claims in published maps and institutional affiliations. 